\title{
Stage IE
}

National Cancer Institute

\section{Source}

National Cancer Institute. Stage IE. NCI Thesaurus. Code C141199.

A stage term referring to Hodgkin or non-Hodgkin lymphoma involving a single extralymphatic site in the absence of nodal involvement. (from AJCC 8th Ed.) 